\title{
FEMINICÍDIO COMO REFLEXO DA CULTURA DE OBJETIFICAÇÃO E DOMINAÇÃO DA MULHER
}

Feminicide as a reflection of the culture of men's objectification and domination over women's

\author{
Ana Luíza Duarte de Carvalho ${ }^{(*)}$ \\ Kamila Montes Ferreira ${ }^{1 * *)}$ \\ Maria Eduarda de Souza Ramos ${ }^{(* * *)}$ \\ Sthefany Cristina da Silva Nunes ${ }^{(* * *)}$
}

\begin{abstract}
Resumo
O presente artigo tem como objetivo abordar o crime de feminicídio, recentemente tipificado no Código Penal brasileiro pela Lei $n^{\circ} 13.104 / 2015$. Busca-se abordar a violência contra a mulher em uma perspectiva histórica, no âmbito social e doméstico, o conceito de feminicídio, o tratamento no direito penal e sua relevância jurídica.
\end{abstract}

Palavras-chave:Direito Penal. Violência Contra a Mulher. Feminicídio.

\begin{abstract}
This article aims to address the crime of feminicide, recently typified in the Brazilian Penal Code by Law No. 13.104/2015. It seeks to address violence against women from a historical perspective, in the social and domestic sphere, bringing the concept of feminicide, the treatment by criminal law and its legal relevance.
\end{abstract}

Keywords: Criminal Law. Violence Against Women. Feminicide.

\section{INTRODUÇÃO}

O presente artigo tem por objetivo explorar e analisar o delito do feminicídio tipificado no ordenamento jurídico brasileiro e perpetrado ao longo do tempo na sociedade, principalmente, por figuras do sexo masculino. Pretende-se traçar um panorama amplo da temática, observando as características deste crime de gênero e sua relação com a inferioridade e objetificação feminina pela coletividade.

Primeiramente, o artigo abordará a violência contra a mulher, a partir de uma perspectiva de gênero, trazendo pontos que buscam esclarecer a origem cultural da

\footnotetext{
${ }^{(*)}$ Graduanda em Direito pela Universidade Federal de Uberlândia, Brasil. E-mail: analuizaduarte@outlook.pt.

${ }^{(* *)}$ Graduanda em Direito pela Universidade Federal de Uberlândia, Brasil. E-mail: kamilamontesf@gmail.com.

${ }^{(* * *)}$ Graduanda em Direito pela Universidade Federal de Uberlândia, Brasil. E-mail: eduardaramos99@outlook.com.

${ }^{(* * * *)}$ Graduanda em Direito pela Universidade Federal de Uberlândia, Brasil. E-mail: sthefany.te@outlook.com.
} 
inferioridade feminina, ressaltando a necessidade de se superar essa condição para que os casos de violência possam ser suprimidos.

Em seguida se trata da violência doméstica e da violência de gênero, pontuando que ainda que ambas estejam intrinsecamente relacionadas, resguardam aspectos próprios que ao serem observados podem auxiliar na elaboração de políticas para seu combate.

A parte 4. traz o enfoque principal do feminicídio, tratando da origem desse termo e como ele se desenvolveu até o presente momento. Além disso, são abordadas as variadas formas e tipos de feminicídio presentes na sociedade em geral, apresentando as características comuns entre eles, mas também ressaltando alguns aspectos próprios.

Por fim, é discutido o feminicídio dentro do ordenamento jurídico brasileiro, trazendo uma abordagem completa que ressalta os principais pontos dessa qualificadora, como ela é aplicada e sua importância, debatendo se a tipificação penal se mantém eficaz no caso em tela.

O método científico utilizado foi o dedutivo, uma vez que a realização do estudo se concentra em pesquisas bibliográficas e jurisprudenciais.

\section{ANÁLISE DA VIOLÊNCIA CONTRA A MULHER SOB A PERSPECTIVA DE GÊNERO}

A violência contra a mulher continua sendo motivo de preocupação no cenário brasileiro contemporâneo, visto como um grave problema social ao redor do mundo. Apesar dos avanços na elaboração de leis mais protetivas, discussões sobre a questão na mídia e a forte atuação de grupos feministas, a violência contra a mulher ainda se faz presente, sendo considerada pela Organização Mundial de Saúde como um problema de saúde pública.

O conceito "violência contra a mulher", frequentemente, engloba a ideia de violência doméstica e violência de gênero, os quais as diferenças serão debatidas ao longo deste artigo. No momento, é importante ressaltar que o termo violência de gênero tem sido utilizado por abranger não somente mulheres, mas crianças e adolescentes, que são diferentes formas de violência derivadas das relações de gênero e poder, sendo a violência contra a mulher, portanto, uma das principais formas da violência de gênero (ARAUJO, 2008). 
Notadamente, a violência contra mulher surge, principalmente, do modelo patriarcalista de organização social. Ao redor do mundo, independentemente das diferenças culturais, políticas ou religiosas, é comum que a organização dos agrupamentos humanos se dê de forma patriarcal. A distinção se inicia com a diferença biológica dos sexos, sob a qual ao longo da história foi construído um sistema de dominação masculina, social e culturalmente. Neste cenário, às mulheres foi dado um papel secundário e uma posição de inferioridade e submissão, o que refletia e, ainda hoje reflete, em discriminações nos mais diversos âmbitos, como profissional, acadêmico, econômico e, até mesmo, jurídico.

Portanto, para entender a violência contra a mulher sob a perspectiva de gênero é fundamental perceber a inferiorização da mulher em um contexto histórico cultural. Destacam-se as palavras de Maria Berenice Dias (2007, p. 15) que elucidam a compreensão do problema na sociedade:

Desde que o mundo é mundo humano, a mulher sempre foi discriminada, desprezada, humilhada, coisificada, objetificada, monetarizada. Ninguém duvida que a violência sofrida pela mulher não é exclusivamente de responsabilidade do agressor. A sociedade ainda cultiva valores que incentivam a violência, o que impõe a necessidade de se tomar consciência de que a culpa é de todos. O fundamento é cultural e decorre da desigualdade no exercício do poder e que leva a uma relação dominante e dominado.

A violência contra mulher é, sem dúvidas, resultado de um processo histórico marcado pela dominação do homem, que ainda hoje cultiva no imaginário humano uma relação de superioridade masculina, na qual a mulher deve sempre obedecer e se comportar da maneira como esperam: uma figura dedicada aos cuidados do lar e dos filhos, amável e dócil, que não tem fala nem lugar próprios.

\subsection{A construção sociocultural da inferioridade feminina}

A dominação do masculino sobre o feminino e a consequente violência contra a mulher, surge da diferença biológica entre os sexos, porém em um sistema socialmente construído que impõe a superioridade do homem sobre a mulher. Assim, para além da diferença biológica ou natural, são discursos e interpretações histórico-culturais que legitimaram a dominação masculina.

Desde os primórdios da humanidade, ao homem coube a caça, a pesca, a agricultura e a guerra, devido a sua força corporal, sendo esta considerada essencial para 
a sobrevivência e proteção do grupo. A mulher, por outro lado, por não possuir a mesma força física, devia se ocupar de atividades menos importantes, como cuidar da organização do lar e da criação dos filhos. Sendo Dias (2010), essa separação culminou ao homem o espaço público, externo, produtor e da dominação, enquanto à mulher o espaço interno, reprodutor e da submissão; e, estes padrões de comportamento, geram um código de conduta.

Dessa forma, a dominação é masculina e o sistema que se legitima é o patriarcalista, no qual cabe aos homens estabelecer normas e punições.

O patriarcalismo é uma das estruturas sobre as quais se assentam todas as sociedades contemporâneas. Caracteriza-se pela autoridade, imposta institucionalmente, do homem sobre a mulher e filhos no âmbito familiar. Para que essa autoridade possa ser exercida, é necessário que o patriarcalismo permeie toda a organização da sociedade, da produção e do consumo à política, à legislação e à cultura. Os relacionamentos interpessoais e, consequentemente, a personalidade, também são marcados pela dominação e violência que têm sua origem na cultura e instituições do patriarcalismo (CASTELLS, 2010, p. 169).

Ao lado dessa organização social surgem discursos normatizadores, que se propuseram a explicar a diferença entre os sexos. Os primeiros discursos remontam à Grécia Antiga, quando os filósofos começaram a tecer ideias sobre o sexo feminino, em sua maioria, depreciativas, focando-se em demonstrar que havia uma essência inferior feminina, da própria natureza.

Aristóteles, por exemplo, é reconhecido como autor da tese de desigualdade natural entre os sexos, por expressar sua crença no domínio masculino, em que o homem é o ser racional que exerce poder sobre a mulher, ser irracional. Para o autor, o homem é mais apto para o comando e, portanto, naturalmente superior à mulher. Evidentemente, seu discurso é baseado também na forma de organização política e social de sua época, mas foi extensamente utilizado para se manter o ideal de superioridade masculina.

Outros filósofos como Jean-Jacques Rousseau e Immanuel Kant defendem a subordinação do sexo feminino, como algo natural e necessário, principalmente, por serem guiadas por instintos naturais passionais, não dotadas de ética e moral tal como o sexo masculino, que se guia por princípios. Semelhantemente, Sigmund Freud retrata a figura feminina como um ser passivo e que não possui senso de justiça, com um complexo de inferioridade devido a inveja causada pela ausência de membro fálico. 
Dessa forma, pode-se perceber que a ideia de dominação entre os sexos é resultado de um produto cultural, socialmente construído e defendido por filósofos e estudiosos ao longo dos séculos. O que é feminino e o que é masculino são padrões definidos pela própria sociedade, em uma perspectiva cultural e social. A submissão das mulheres é fundada nesta ordem social, na qual se concedeu mais direitos e poderes aos homens, tanto politicamente no âmbito público, quanto sexualmente no âmbito privado, sendo que este último tem legitimado a violência contra a mulher ao longo do tempo a ponto tal de naturalizá-la.

\subsection{A cultura de objetificação e dominação da mulher}

Como discorrido no tópico anterior, aspectos históricos, culturais e sociais fizeram com que a figura feminina fosse compreendida como inferior e irracional. Este entendimento é o que levou e, ainda hoje mantém, a ideia de que a mulher deve submissão ao homem e, portanto, a ele é dado o domínio e o controle sobre o corpo feminino.

Estes estereótipos têm resultado nas mais diversas formas de violência contra a dignidade da mulher, mas todos justificados por uma lógica patriarcal de superioridade masculina. Os estereótipos também se ligam ao conceito de objetificação, que consiste em analisar alguém como um objeto, desconsiderando seus aspectos sentimentais e psicológicos (LOURENÇO; ARTEMENKO; BRAGAGLIA, 2014).

A objetificação da mulher é visível, principalmente, em propagandas. O foco de diversas peças publicitárias é o atributo sexual e físico feminino, dispensando qualquer outro apelo emocional. Assim, para além da imagem de um sexo frágil e submisso, o feminino passa a ser também objeto de satisfação dos desejos masculinos. Os corpos das mulheres são exibidos de forma sexualizada e como uma mercadoria, enquanto o poder intelectual da mulher pouco importa.

A mulher é retratada de forma estereotipada, encaixando-se em padrões socialmente aceitos. A mulher perfeita: magra, alta, com músculos bem definidos (mas não exageradamente), lábios chamativos, cabelos lisos e sedosos. Esta é a imagem vendida para os homens, feita de homens para homens e que está longe de representar verdadeiramente as mulheres. Entretanto, é neste padrão que as mulheres acreditam que devam se encaixar, o que gera diversas frustrações em si mesmas, pois está longe de ser uma forma alcançável na realidade. 
Neste sentido, a objetificação da mulher se torna mais uma das formas de domínio do homem, mais uma forma de controle sobre os corpos e mentes das mulheres. Elas não só devem submissão dentro do lar, cuidando da organização da casa e da educação dos filhos, como agora também devem estar sempre "bonitas", no sentido de se produzirem para seus maridos em um aspecto atraente e sexualizado, para atenderem a um padrão social de como deve ser sua aparência e do que é feminilidade.

\section{A VIOLÊNCIA DE GÊNERO E A VIOLÊNCIA DOMÉSTICA NO CONTEXTO DO FEMINICÍDIO}

Para a tipificação do crime de feminicídio, é necessário que sejam observadas duas vertentes referentes a motivação do crime, sendo elas: a mulher precisa ter sido morta decorrente de violência doméstica ou familiar ou pela discriminação de sua condição de ser mulher. Nesse ponto, observa-se que, embora tais causas estejam entrelaçadas e ainda que ambas decorrem de um mesmo processo histórico culturalmente enraizado na cultura machista, a diferenciação de ambos os conceitos é de extrema importância para reconhecer as demandas do gênero feminino com as devidas peculiaridades para que se possa elaborar novas políticas para seu combate.

Nesse ponto, a violência doméstica refere-se quando o delito é cometido entre os membros que habitam em um ambiente familiar em comum e ocorre em decorrência dessa proximidade. No âmbito do feminicídio, é denominado por alguns doutrinadores de "feminicídio íntimo" e ocorre quando o agressor tem uma convivência mais íntima com a vítima, sendo, em sua maioria, provocado pelos maridos, ex-namorados ou parceiros durante um relacionamento.

Ademais, cabe salientar que, segundo dados extraídos pelo Mapa da Violência 2015: Homicídio de Mulheres no Brasil (Flacso/OPAS-OMS/ONU Mulheres/SPM, 2015), dos 44.762 feminicídios registrados no ano de 2013 no Brasil, 50,3\% destes foram cometidos por familiares, sendo que em 33,2\% desses casos, o delito foi cometido pelo seu atual ou ex-parceiro. Logo, depreende-se que a violência doméstica é a principal motivação e principal causa do crime de feminicídio.

No cenário brasileiro, a grande parcela significativa dos casos de feminicídio são praticados por alguém que mantém uma relação de afeto com a vítima, diferentemente dos demais países da América Latina, em que tal delito é associado a questões de 
gênero, como a violência sexual. Assim, adentra-se na esfera do que seria a violência de gênero no contexto do feminicídio, diferenciando-a do feminicídio íntimo.

A violência de gênero, caracteriza-se pela ocorrência de atos violentos, podendo ocasionar a morte, em decorrência do gênero ao qual as vítimas pertencem. Ou seja, a violência ocorre porque alguma das pessoas envolvidas é homem ou mulher. Todavia, na realidade, a expressão violência de gênero se remete diretamente à violência contra mulher, uma vez que as mulheres são as grandes vítimas da violência.

Portanto, a violência de gênero relaciona-se com padrões de crenças e papéis sociais decorrentes de gênero, todavia, apesar de ser maioria, tal violência não é exclusiva das mulheres. Se mulheres sofrem violência de gênero em casos de abuso sexual em transportes públicos (pois tem a ver com considerar o corpo feminino um objeto de sujeição masculina, o que corresponde a uma determinada crença sobre feminilidade e sobre os corpos das mulheres - e os lugares onde eles podem estar), homens podem estar sofrendo violência de gênero quando se envolvem em conflitos interpessoais fatais e acidentes de carro (afinal, "não levar desaforo pra casa" dizem muito sobre a crença em um determinado modelo de masculinidade extremamente lesivo para pessoas que performatizam o gênero masculino) (ZAPATER, 2016).

Para a identificação desse tipo de violência é importante observar dada situação social e inverter os papéis da vítima: caso haja uma aversão pelo não cumprimento de referida expectativa do que aconteceria com aquela vítima na determinada situação, ousa-se dizer que ali há padrões sociais pré-determinados culturalmente. Ou seja, tal noção já é "pré-compartilhada" em detrimento de ideais discriminatórios enraizados naquele meio social.

\section{FEMINICÍDIO}

\subsection{Origem do termo}

O feminicídio ou femicídio pode ser morfologicamente extraído da palavra em inglês "feminicide" e interpretado em sua generalidade como o assassinato de mulheres por homens que são motivados diversamente por sentimentos de ódio, desprezo, prazer, relação de superioridade ou propriedade sob indivíduos do sexo oposto. Em geral, o que caracteriza essas mortes são traços culturais de dominação e desigualdade traçados ao longo da história e reforçados por uma cultura sexista em que as mulheres são vistas 
como vulneráveis, inferiores e como um objeto, retirando delas o caráter humanizador e reforçando a "permissão" para que sejam violentadas de alguma forma.

Cabe ressaltar que alguns pesquisadores costumam diferenciar o femicídio como o assassinato de mulheres e o feminicídio como o assassinato de mulheres por motivações decorrentes exclusivamente de seu gênero, neste último caso, alguns defendem a negligência do Estado com relação a estas situações, ocasionando uma ofensa ainda maior contra a humanidade. Como estes debates são muito recentes, na prática, não encontram tanta relevância, uma vez que ambos os conceitos são recorrentemente utilizados para relacionar a mesma situação.

O conceito de feminicídio engloba uma variedade de violências proferidas contra as mulheres que resultam em morte, destacando-se, ao longo da história, ocorrências como as mortes de mulheres consideradas bruxas, os infanticídios de meninas por motivos culturais e até mesmo os crimes justificados como "para proteção da honra" masculina. Sendo assim, a ativista demonstrou uma característica que ocorre ao longo do tempo por motivações variadas nas sociedades, mas que culmina na morte de mulheres.

Atualmente, a discussão quanto ao tema tem sido amplamente ressaltada por diversos movimentos ativistas dos direitos das mulheres ao redor do mundo, sendo que cerca de 17 países da América Latina já utilizam o termo dentro de seus códigos criminais, como forma de agravante quando é encontrado indícios relacionados ao sexismo e desprezo à condição das mulheres.

\subsection{Tipos de feminicídio}

O feminicídio pode se manifestar em diversos contextos e cenários diferentes, ainda que não se tenha uma completa disposição de suas formas e tipos, há algumas circunstâncias gerais podem ser observadas e utilizadas para auxiliar na compreensão e na prevenção e proteção das mulheres.

Os tipos mais observados por pesquisadores e ativistas são os feminicídios derivados de violência doméstica ou no contexto familiar. Considerando que a família é uma instituição social que geralmente está inserida dentro de um panorama patriarcal, as mulheres nesse cenário são vistas como propriedades de seus parceiros, dando a eles a ideia de que podem dispor das esposas ou companheiras como bem entender. 
Existem alguns fatores que podem aumentar a insegurança das mulheres nestes casos, como a diferença de idade entre os parceiros, dependência econômica da mulher ou mesmo do parceiro, e o histórico reiterado de abusos e agressões. Ainda que não haja uma regra para os casos, pode-se utilizar desses pontos para entender melhor o contexto e prevenir que uma violência fatal se concretize.

O assassinato por parceiro em condição familiar também pode ser identificado como feminicídio íntimo e nesses casos há uma tendência social de associar o delito com um motivo passional ou um momento de grande perturbação emocional que não podia ser previsto, o que dificulta a tipificação do delito como feminicídio e o naturaliza socialmente.

Outra forma observada é o chamado feminicídio sexual, o qual se dá em circunstâncias em que mesmo a vítima desconhecendo seu agressor, sua morte é precedida de violência sexual. Este tipo de feminicídio pode ser verificado em todas as camadas sociais, sem motivações raciais, econômicas, sociais ou outras. Nesse caso, o agressor enxerga a vítima como um objeto que pode ser violentado e descartado, sendo que a morte seria uma forma de eliminar vestígios e testemunhas.

Cabe ressaltar, ademais, o feminicídio corporativo, que corresponde a um cenário de exploração e tráfico sexual de mulheres, posto que a morte é utilizada como uma forma de vingança ou tratamento disciplinar. As redes de tráfico sexual compõem um negócio econômico extremamente lucrativo e muitas vezes contam com a proteção e vista grossa das entidades que deveriam resguardar as vítimas, como policiais, políticos, órgãos de segurança estatal, etc. Este "negócio" implica diretamente na coisificação feminina, transformando as mulheres em objetos, permitindo que elas sejam descartadas por motivos de doenças, ameaças de fugas ou por não cumprirem com o que é estabelecido.

Salienta-se que não apenas nos casos de tráfico é identificado o feminicídio corporativo, mas também no exercício geral da prostituição. As mulheres nessa situação são extremamente mais vulneráveis do que a população feminina em geral, pois ao tempo em que o cliente paga pelas relações sexuais, sente-se na garantia de dispor daquela mulher.

Além dessas tipologias, também pode-se considerar como feminicídio situações que incluem mortes por conexão, por exemplo, quando mulheres que são companheiras de criminosos envolvidos com tráfico são mortas para demonstrar sinal de vingança ou "recado" para seus parceiros. Se enquadra nesta forma, ainda, feminicídios sexuais 
sistêmicos, os quais são precedidos de sequestro, tortura e violência sexual, como nos casos de "serial killers". Pode-se encaixar, por fim, os feminicídios com marcas de racismo, que advêm de origens étnicas, raciais ou por traços da mulher, como o preconceito em relação à orientação sexual, ocasionando feminicídiostransfóbicos e lesbofóbicos.

Convém considerar como feminicídio as execuções femininas em conflitos armados, as quais são relevantes para o estudo ainda que sejam verificados em minorias étnicas e sociais, uma vez que estas mulheres são vistas como inferiores e sua morte é justificada como uma limpeza social. Alguns autores consideram, enfim, o feminicídioinfantil, sendo este a situação em que uma criança do sexo feminino morre por maus tratos ou violência daqueles que legalmente tem o dever de protegê-la.

\section{FEMINICÍDIO NO ORDENAMENTO JURÍDICO-PENAL BRASILEIRO}

\subsection{Abordagem histórica}

Para que se compreenda a influência que a política de armas adotada pelo país pode apresentar dentro do contexto de vítimas fatais da violência doméstica, insta que seja estudado o delito nomeado 'feminicídio'. Todavia, este conceito é novo dentro do contexto do direito penal brasileiro, uma vez que o Brasil possui um histórico de Códigos discriminatórios, reflexos de uma sociedade patriarcal e machista.

O primeiro código elaborado e sancionado, após a Independência do Brasil, foi o Criminal de 1830, no qual é possível se verificar a proteção da mulher em alguns dispositivos, como na proibição de pena de morte à grávida. Não obstante, a discriminação enraizada na sociedade foi reproduzida na legislação criminal da época. Um exemplo é o adultério, que somente poderia ser praticado pelo homem, dispensando a comprovação do fato, o que significava que, na prática, a mulher era a única penalizada e a infidelidade masculina não acarretava qualquer consequência. Além disso, no que se refere aos crimes sexuais, ficava clara a intenção do legislador: tutelar pela honra, não pela dignidade sexual e física feminina, ou seja, o objetivo não era proteger as mulheres em si, mas sim a sua virgindade e a honestidade das famílias.

Em 1980, o novo Código Penal entrou em vigor e não houve nenhuma alteração significativa que favorecesse mulher e ainda era evidente o teor discriminatório em relação ao gênero. Por exemplo no que tangia ao estupro, que analisava questões de caráter subjetivo da mulher que figurava como vítima, como a honestidade da mesma. 
Assim, nahipótese de mulher honesta, o casamento com o algoz extinguia a punibilidade do crime sexual, determinação expressa do artigo 276 de tal Código. Por meio do matrimônio, o homem "corrigia" a conduta ilícita praticada, o que significava, em muitos casos, que as vítimas se viam forçadas a casar com seus agressores.

O último Código Penal a entrar em vigor é o Decreto 2848/1940, o qual está vigente até os dias atuais e já foi alterado por diversos dispositivos, visando atingir os interesses sociais. Tal Código foi considerado tão discriminatório quanto os anteriores, sendo que somente com a promulgação da Constituição de 1988 passou-se a tutelar as garantias da mulher de forma mais ampla. Inicialmente, o Título VI, por exemplo, era denominado de "crimes contra os costumes", o que demonstra uma maior proteção à moralidade e não aos indivíduos. A denominação do Título foi modificada apenas em 2009 para "crimes contra a dignidade sexual" com o advento da Lei n 12.015 (PONTE, 2015).

Insta abordar, também, o progresso que se refere à liberdade em relação ao cônjuge, o qual deixa de ter direito sobre o corpo da companheira. Isto significa que o marido não mais poderia mais dispor do corpo da mulher conforme sua vontade. Outro avanço se deu com advento da Lei $\mathrm{n}^{\circ} 8.072$ de 1990, a partir do qual o estupro e 'atentado violento ao pudor' (atualmente revogado), artigos 213 e 214, respectivamente, passaram a ser considerados crimes hediondos, oferecendo não só maior proteção às mulheres, mas também punição mais severa aos criminosos, inibindo em tese os delitos.

Outro avanço importante a ser ressaltado diz respeito às disposições referentes ao crime de adultério, que foram revogadas por meio da Lei $\mathrm{n}^{\circ} 11.106$ de 2004, tendo em vista modificações culturais em favor das mulheres, bem como a expressão "mulher honesta", contida nos delitos dos dois códigos anteriores, que também foi abolida.

\subsection{A Lei no $13.104 / 2015$}

Inicialmente protocolado no Senado Federal o projeto de lei como PL 292/2013, havia a proposta de alteração do art. 121 do Código Penal, com a seguinte redação:

Art. $121[\ldots]$

$\S 7^{\circ}$ Denomina-se feminicídio à forma extrema de violência de gênero que resulta na morte da mulher quando há uma ou mais das seguintes circunstâncias:

I - relação íntima de afeto ou parentesco, por afinidade ou consanguinidade, entre a vítima e o agressor no presente ou no passado; 
II - prática de qualquer tipo de violência sexual contra a vítima, antes ou após a morte;

III - mutilação ou desfiguração da vítima, antes ou após a morte:

Pena - reclusão de doze a trinta anos.

$\S 8^{\circ}$ A pena do feminicídio é aplicada sem prejuízo das sanções relativas aos demais crimes a ele conexos. (SENADO FEDERAL, 2013)

As duas primeiras circunstâncias previstas descrevem as definições de feminicídio íntimo e não íntimo, enquanto a última descreve hipótese de violência cometida pelo ódio ao feminino e o desprezo pelo corpo da mulher (RODRIGUES, 2016).

Durante as discussões, o projeto foi encaminhado à Comissão de Constituição e Justiça $(\mathrm{CCJ})$ e para análise da Procuradoria da Mulher do Senado Federal, sofrendo algumas alterações no texto. Ao final do processo, a Lei n. ${ }^{\circ} 13.104 / 2015$ foi promulgada com a seguinte redação, ficando conhecida como Lei do Feminicídio:

Homicídio simples

Art. 121. [...]

Homicídio qualificado

$\S 2^{\circ}[\ldots]$

Feminicídio

VI - contra a mulher por razões da condição de sexo feminino:

[...]

$\S 2^{\circ}$-A Considera-se que há razões de condição de sexo feminino quando o crime envolve:

I - violência doméstica e familiar;

II - menosprezo ou discriminação à condição de mulher.

[...]

Aumento de pena

$[\ldots]$

$\S 7^{\circ}$ A pena do feminicídio é aumentada de $1 / 3$ (um terço) até a metade se o crime for praticado:

I - durante a gestação ou nos 3 (três) meses posteriores ao parto;

II - contra pessoa menor de 14 (catorze) anos, maior de 60 (sessenta) anos ou com deficiência;

III - na presença de descendente ou de ascendente da vítima.

Art. $2^{\circ} \mathrm{O}$ art. $1^{\circ}$ da Lei no 8.072, de 25 de julho de 1990, passa a vigorar com a seguinte alteração:

"Art. $1^{\circ}[\ldots]$

I - homicídio (art. 121), quando praticado em atividade típica de grupo de extermínio, ainda que cometido por um só agente, e homicídio qualificado (art. $121, \S 2^{\circ}$, I, II, III, IV, V e VI)."

Art. $3^{\circ}$ Esta Lei entra em vigor na data da sua publicação." (BRASIL, 2015)

A este crime atribuiu o legislador a qualidade de hediondo, incluindo-o no inciso I do artigo $1^{\circ}$ da Lei n. ${ }^{\circ} 8.072 / 90$ (Lei dos Crimes Hediondos). 


\subsubsection{Feminicídio como uma qualificadora}

À conduta que se expressa na morte violenta com características e contextos especiais de mulheres é dado o nome jurídico de feminicídio. Portanto, o feminicídio nada mais é do que o reconhecimento do assassinato de mulheres que ocorre no Brasil, dando a este tipo de violência um nome jurídico, bem como sanções próprias, reconhecendo, ainda, a violação direta aos direitos humanos das mulheres e visando dar maior proteção a elas.

É dentro deste contexto, de uma tendência a desconstrução dos estigmas de gênero dentro do âmbito penal, que se mostra essencial a compreensão do surgimento, em 2015, do termo 'feminicídio' no bojo do Código Penal vigente. Assim, a priori, insta que seja fique clara a diferença entre os termos ‘femicídio' e ‘feminicídio'. É simples: o primeiro refere-se, unicamente, ao ato de praticar homicídio contra uma mulher, ao passo que o segundo se relaciona com a pratica do mesmo crime, porém motivado por razões de gênero.

Antes da Lei $\mathrm{n}^{\circ} 13.104 / 2015$, não havia nenhuma punição especial ao fato de o homicídio ser praticado contra a mulher, motivado por questões ligadas à posição de mulher como gênero. Em outras palavras, o feminicídio era punido, de forma genérica, como homicídio puro e simples (art. 121 do CP). A depender do caso concreto, o feminicídio (que ainda não tinha esta denominação) poderia ser enquadrado como sendo homicídio qualificado por motivo torpe (inciso I do $\S 2^{\circ}$ do art. 121) ou fútil (inciso II), havendo, ainda, a possibilidade de se encaixar a situação concreta no previsto que prevê o inciso IV (dificuldade da vítima de se defender).

A Lei de 2015 veio, então, alterar esse panorama e previu, de forma expressa, que o feminicídio deverá ser punido como homicídio qualificado. Trata-se então da tipificação de um termo para conceituar práticas que, contrariamente, são antigas e enraizadas em uma sociedade notadamente patriarcal.

O questionamento que surge, então, é se a Lei Maria da Penha já não trazia essas mesmas punições da qualificadora. Mas, antes de respondê-lo, é de suma importância que se realize uma gênese sobre esta Lei de tamanho peso para as mulheres dentro do Direito Penal brasileiro.

O caso de Maria da Penha Maia Fernandes, que deu ensejo à publicação da referida lei brasileira $\left(n^{\circ} 11.340\right)$, reflete as graves consequências da presença de arma de fogo em um ambiente doméstico violento. Em 1983, seu esposo tentou matá-la com 
um tiro de espingarda e, apesar de ter escapado da morte, Maria da Penha restou paraplégica. Quando criou coragem para denunciar seu agressor, Maria se deparou com uma situação que muitas mulheres enfrentavam neste caso: medo de tomarem alguma providência por se sentir ameaçada pelo agressor e, principalmente, por incredulidade por parte da Justiça brasileira. A defesa do agressor sempre alegava irregularidades no processo e o suspeito acabava respondendo em liberdade.

Maria da Penha acionou o Centro pela Justiça e o Direito Internacional (CEJIL) e o Comitê Latino Americano e do Caribe para a Defesa dos Direitos da Mulher (CLADEM) e estes, por sua vez, encaminharam seu caso para a Comissão Interamericana de Direitos Humanos da Organização dos Estados Americanos (OEA), em 1998. Todavia, o caso só foi solucionado em 2002, quando o Estado brasileiro foi condenado por omissão e negligência pela Corte Interamericana de Direitos Humanos. Assim, o Brasil teve que se comprometer em reformular suas leis e políticas em relação à violência doméstica.

Dentro desse contexto nasceu, em agosto de 2006, a Lei $\mathrm{n}^{\mathrm{o}} 11.340$ visando proteger a mulher da violência doméstica e familiar. Esta lei serve para todas as pessoas que se identificam com o sexo feminino, heterossexuais ou não. E é considerada uma das mais modernas e completas no que se refere ao enfrentamento da violência doméstica contra a mulher, uma vez que possui uma abordagem integral, intersetorial e interdisciplinar. É importante, entretanto, que seja levada a sério no contexto de busca por uma melhor efetividade da lei.

Realizada a contextualização da lei, é cabível a análise comparativa da qualificadora 'feminicídio' em relação à Lei Maria da Penha. A última não traz um rol de crimes em seu texto, mas regras processuais instituídas para proteger a mulher vítima de violência doméstica, sem tipificação de condutas. Assim, compreende-se que o feminicídio não constava previsto na Lei 11.340/2006, apesar de que suas medidas protetivas podem ser aplicadas à vítima de feminicídio.

De volta, enfim, à análise da lei 13.104, tem-se que esta entrou em vigor no ano de 2015 e alterou o código penal de forma a incluir o feminicídio como modalidade de homicídio qualificado em seu $\S 2^{\circ}$ VI, prevendo pena de 12 a 30 anos. Além disto, o $\S$ $2^{\circ}$-A do art. 121 foi acrescentado a fim de explicar as situações em que o delito cometido se encaixará no termo "razões da condição de sexo feminino", quais são: violência doméstica e familiar (inciso I) e menosprezo ou discriminação à condição de mulher (inciso II). 
No que se refere à "violência doméstica e familiar", foco de estudo do presente artigo, o legislador abriu margem para uma interpretação mais ampla do conceito de feminicídio, uma vez que, pela interpretação literal do inciso, não seria necessário discutir os motivos que levaram o autor a cometer o crime. Isto significaria que, tendo sido praticado o homicídio (em sua forma tentada ou consumada) contra a pessoa do sexo feminino em situação de violência doméstica, restaria materializado o feminicídio. Todavia, é preciso que se realize uma contextualização e interpretação mais sistemática, socorrendo-se definição de "violência doméstica e familiar" tal qual se encontra no art. $5^{\circ}$ da Lei $n^{\circ} 11.340 / 2006$, a qual leva a compreender que mesmo nos casos de violência familiar e doméstica (inciso I do $\S 2^{\circ}$-A do art. 121), será indispensável que o crime envolva motivação baseada no gênero.

Tem-se, também, que se trata de um crime comum, uma vez que o sujeito ativo poder ser qualquer pessoa (e não somente um homem), ao passo que o sujeito passivo carrega a obrigatoriedade do sexo feminino. O delito também pode se apresentar na forma tentada ou consumada, bem como ser praticado com dolo direto ou eventual. Além disso, no que se refere à natureza qualificadora do feminicídio, esta se relaciona diretamente com a esfera interna do agente, sendo subjetiva. Por esse motivo, não se pode falar em feminicídio privilegiado e, em caso de concurso de pessoas, não se comunica aos demais coautores ou partícipes, salvo se tiverem a mesma motivação.

A Lei $n^{\circ} 13.104 / 2015$ também prevê três causas de aumento de pena exclusivas para a qualificadora 'feminicídio' em seus incisos do $\S 7^{\circ}$ do art. 121. Desta forma, temse que a pena será aumentada se: no momento do crime, a vítima estava grávida ou havia apenas 3 meses que ela tinha tido filho; se, no momento do crime, a mulher (vítima) tinha menos de 14 anos, era idosa ou deficiente; se delito foi praticado na presença de descendente ou de ascendente da vítima. Cabe ressaltar, porém, que é necessária a presença do dolo, isto é, o agente deverá ter ciência das situações expostas para que incidam as causas de aumento.

Algumas dessas causas de aumento especiais são também previstas como agravantes genéricas no art. 61, II, do Código Penal. No caso de feminicídio, o magistrado deverá aplicar apenas as causas de aumento, não podendo fazer incidir as agravantes que tenham o mesmo fundamento sob pena de incorrer em bis in idem. 


\subsubsection{Natureza jurídica}

Quanto a natureza jurídica da qualificadora feminicídio existem divergências doutrinárias, sendo que alguns a consideram uma qualificadora de natureza subjetiva (relacionada a motivação do crime) e outros como de natureza objetiva (ligadas ao meio e modo de execução).

Parece mais acertado a consideração do feminicídio como uma qualificadora de natureza subjetiva, visto que é utilizada a expressão "por razões da condição de sexo feminino", portanto, indicando a motivação e não a forma de execução do crime, uma vez que há uma relação de causalidade entre a circunstância e a conduta praticada pelo agente. Para tanto, é necessário que a vítima não seja apenas mulher, mas que esta condição seja o motivo do homicídio.

Como consequências notáveis desta qualificação, há a impossibilidade de cumular o feminicídio com as circunstâncias privilegiadoras, previstas no art. $121, \S 1^{\circ}$ do Código Penal, bem como em hipótese de concurso de pessoas, o feminicídio não se comunica aos demais coautores ou partícipes (RODRIGUES, 2016).

\subsubsection{Sujeitos}

No que se refere ao sujeito ativo do crime de feminicídio, a lei não faz exigência de nenhuma qualidade ou condição específica, sendo que este pode ser praticado por qualquer pessoa, basta apenas que haja uma das hipóteses do art. 121, §2-A do Código Penal, como violência doméstica e familiar ou menosprezo ou discriminação à condição de mulher.

Quanto ao sujeito passivo, a redação da Lei n. ${ }^{\circ} 13.104 / 15$ traz que se considera feminicídio "contra a mulher por razões da condição de sexo feminino", de forma que está atrelado ao sexo biológico da vítima, portanto, a vítima deve pertencer biologicamente ao sexo feminino. Entretanto, há nas doutrinas posições que entendem que pessoas não pertencentes ao sexo feminino biologicamente também podem ser consideradas mulheres para os efeitos da qualificadora, como os transexuais desde que juridicamente reconhecida sua condição de mulher (RODRIGUES, 2016). 


\subsubsection{Causas especiais de aumento}

Quanto às causas especiais de aumento, nota-se que a Lei n. $^{\circ}$ 13.104/15 acrescentou o $\$ 7^{\circ}$ ao art. 121 do Código Penal. Este artigo traz que a pena aplicada ao homicídio qualificado pelo feminicídio poderá ser aumentada de um terço até a metade em algumas situações, sendo estas:

$\S 7^{0}$ A pena do feminicídio é aumentada de $1 / 3$ (um terço) até a metade se o crime for praticado:

I - durante a gestação ou nos 3 (três) meses posteriores ao parto;

II - contra pessoa menor de 14 (catorze) anos, maior de 60 (sessenta) anos, com deficiência ou portadora de doenças degenerativas que acarretem condição limitante ou de vulnerabilidade física ou mental;

III - na presença física ou virtual de descendente ou de ascendente da vítima;

IV - em descumprimento das medidas protetivas de urgência previstas nos incisos I, II e III do caput do art. 22 da Lei $\mathrm{n}^{\circ} 11.340$, de 7 de agosto de 2006 (BRASIL, 1940).

\subsection{Importância de regulamentação especial e direito penal simbólico}

Dada a compreensão do feminicídio como um termo que surgiu recentemente no Código Penal assumindo o papel de uma qualificadora, é essencial que se compreenda o significado deste passo para a mulher brasileira no contexto sociocultural no qual está inserida.

Deve-se enxergar o feminicídio como um crime distinto do homicídio comum, uma vez que é cometido contra uma mulher pelo simples fato de ser mulher, deixando evidente o contexto de misoginia. Desta forma, para compreender o significado e a importância da regulamentação específica, é necessário mergulhar nas raízes de um país marcado pelo patriarcado, com uma cultura que incita e habitua a sociedade a enxergar e tratar a mulher como um ser inferior.

Enraizou-se, junto à coletividade, uma cultura patriarcal que foi criando e reforçando paradigmas. No princípio da história humana, as sociedades eram tribais e coletivistas. Com a sedentarização, entretanto, a realidade foi se modificando a medida em que houve uma maior valorização da ideia de posse e propriedade. Assim, as relações passaram a se tornar monogâmicas de forma a garantir a herança dos filhos legítimos e, então, o corpo e sexualidade femininos passaram a ser controlados. 
O patriarcado se consolidou de forma a alicerçar a sociedade contemporânea, na qual o homem assumiu um papel de autoridade institucional, sendo colocado acima das mulheres não somente no ambiente domiciliar e familiar, mas também em outras organizações sociais. $\mathrm{O}$ papel da mulher como social, profissional, física e emocionalmente inferior ao homem veio então sendo reforçado até os dias atuais.

A luta das mulheres pelo reconhecimento de seus direitos e pelo tratamento igualitário em todos os âmbitos na vida social não é recente e foram várias suas conquistas. Todavia, não se pode deixar de perceber como, em pleno século XXI, ainda existem fortes reflexos desta sociedade doente que se consolidou sobre o patriarcado, tendo o machismo como seu principal sintoma.

É neste contexto de ser tratada como inferior e objeto de posse do homem que a mulher se vê sendo agredida, inclusive dentro de sua própria casa. Conforme o Instituto Maria da Penha, a cada dois segundos uma menina ou mulher é vítima de violência física. E este dado não inclui os ataques verbais, o controle psicológico e tampouco situações que expõem mulheres a constrangimentos diariamente.

Todavia, dado o importante valor simbólico da criação da qualificadora feminicídio uma vez que chama atenção da sociedade e retira a violência da invisibilidade, é necessário que se reflita acerca do fato de que a busca por soluções através da pena não se mostra, por si só, efetiva. Isto é, mostra-se a expansão do poder punitivo do Estado sem um resultado na redução da criminalidade.

Neste contexto, a qualificadora significa apenas a aplicação de uma pena mais grave para o homicídio motivado por razões de gênero, tratando-se da clássica reação do Direito Penal, que somente ocorre a posteriori, quando ocorrido o crime, como repressão, e não tutela. Assim, a compreensão da complexidade do delito, para além da sua tipificação, permite a busca por soluções mais efetivas e voltadas à mulher.

\section{CONSIDERAÇÕES FINAIS}

O que se nota, é uma realidade de violência, insegurança e desrespeito para com a mulher, reflexos de um machismo historicamente estruturado. Desta forma, mesmo que ainda vivamos em uma sociedade marcada pelo patriarcalismo, é clara a importância da Lei 13.104/2015, que vem para dar maior visibilidade e alarme aos diversos tipos de violência contra a mulher, sendo um importante passo rumo proteção à mulher e desconstrução de um tratamento desigual por tanto tempo camuflado na sociedade. 
Ainda que os resultados da proposta sejam gradativos e, em grande parte, tenham um valor que é muito mais simbólico, a iniciativa convida a sociedade a repensar os estereótipos, as ideias pré-concebidas de papéis sociais denominados masculinos ou femininos e as crenças limitantes que inserem as mulheres em um grupo social inferior aos homens e sujeito à vontade destes.

O feminicídio é grave e existe, principalmente como consequência de uma violência cotidiana e banalizada socialmente. Assim, se mostra cada vez mais importante a atuação do executivo, judiciário e legislativo no sentido de dar maior visibilidade a uma questão tão relevante e presente na realidade da mulher, de forma a atingir essenciais mudanças, que não se limitam ao direito penal, mas à sociedade como um todo.

\section{REFERÊNCIAS}

ARAUJO, Maria de Fátima. Gênero e violência contra a mulher: o perigoso jogo de poder edominação. Psicol. Am. Lat., México, n. 14, out. 2008. Disponível em: $<$ http://pepsic.bvsalud.org/scielo.php?script=sci_arttext\&pid=S1870-

350X2008000300012\&lng=pt\&nrm=iso $>$. Acesso em: 31 out. 2019.

BRASIL. Decreto-Lei 2.848, de 07 de dezembro de 1940. Código Penal. Diário Oficial da União, Rio de Janeiro, 31 dez. 1940.

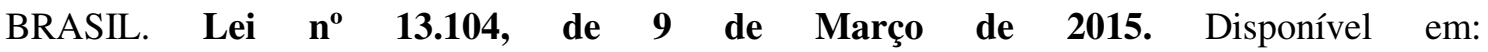
<http://www.planalto.gov.br/ccivil_03/_Ato2015-2018/2015/lei/L13104.htm>. Acesso em: 31 out. 2019.

CASTELLS, Manuel. O poder da identidade. São Paulo: Paz e Terra, 2010.

DIAS, Maria Berenice. Manual de Direito das Famílias. 7ª ed. São Paulo: Ed. RT, 2010.

LOURENÇO, Ana Carolina Silva; ARTEMENKO, Natália Pereira; BRAGAGLIA, Ana Paula. A "objetificação" feminina na publicidade: uma discussão sob a ótica dos estereótipos. In: CONGRESSO DE CIêNCIAS DA COMUNICAÇÃO NA REGIÃO SUDESTE, 19., 2014, Vila Velha. Anais...Vila Velha: Intercom, 2014. p. 1 - 15.

PONTE, Sarah Venâncio. A violência de gênero e a sua repercussão na legislação brasileira com ênfase na nova lei do feminicídio.2015. 86 f. TCC (Graduação) - Curso de Direito, Universidade Federal do Ceará, Fortaleza, 2015.

RODRIGUES, Annelise Siqueira Costa. Feminicídio no Brasil: uma reflexão sobre o direitopenal como instrumento de combate à violência de gênero. 2016. 83 f. Tese (Doutorado) Curso de Direito, Universidade Federal Fluminense, Volta Redonda, 2016.

SENADO FEDERAL. Relatório Final da Comissão Parlamentar Mista de Inquérito parainvestigar a situação da mulher vítima de violência no Brasil. 2013, p. 1002. 
ZAPATTER, MAÍRA.Violência contra as mulheres e violência de gênero: qual a diferença?. Disponível em:<http://www.justificando.com/2016/03/10/violencia-contra-mulheres-violenciadomestica-e-violencia-de-genero-qual-a-diferenca/ $>$. Acesso em: 10 nov. 2019.

(Recebido em novembro de 2020; aceito em dezembro de 2020). 